\title{
Stimulation of lignin synthesis via the PAL- associated metabolic pathway in wheat plants (Tríticum aestívum L.)
}

\author{
Pavel Feduraev ${ }^{*}$, Artem Pungin, Anastasiia Riabova, Elina Tokupova, and Liubov Skrypnik \\ Immanuel Kant Baltic Federal University, Universitetskaya str., 2, 236040 Kaliningrad, Russia
}

\begin{abstract}
The paper demonstrates an approach to increasing the accumulation of lignin in plants of soft wheat (Tríticum aestivum L.) at the early stages of ontogenesis, by means of substrate stimulation of the key enzyme of the synthesis of phenylpropanoids - phenylalanine-ammonialyase. It was shown that plants grown on nutrient media containing phenialanine or tyrosine at a concentration of $500 \mu \mathrm{M}$ significantly increased the lignin content of cell walls compared to controls.
\end{abstract}

\section{Introduction}

One of the principle crops, both in our country and around the world, is wheat (Triticum aestivum L.). However, the most typical agronomic practice in wheat cultivation remains monoculture cultivation. This type of cultivation is associated with a number of negative effects, and primarily with a decrease in plant resistance to both biotic and abiotic environmental factors. Thus, the search for ways to increase plant resistance remains relevant. In turn, the systemic acquired plant resistance, as a complex of metabolic and functional states, can be realized, through intensification of biosynthesis of polymeric aromatic structures, such as lignin.

Lignin synthesis is a key innovation in the evolution of vascular plants. Lignin is a phenolic polymer that is mainly deposited in the secondary cell wall during the last stages of cellular differentiation. It displaces the water phase of cell wall, covering the cellulose and matrix polysaccharides, and provides increased mechanical strength and a watertight barrier of plant cell [1]. Lignin is also necessary to strengthen vascular cells (conductive tissue cells), which carry water under the negative pressure resulting from transpiration. The importance of lignin in these tissues is demonstrated by vascular collapse in lignindeficient plants [2].

Along with the ability to provide mechanical support to the axial structures of the plant, lignin, together with other cell wall elements, acts as a nonspecific immunity factor. Thus, lignin is able to determine plant resistance not only from invasive biotic factors, but also from changing environmental factors. It has been shown that lignin or lignin-like phenolic polymers are deposited in response to biotic and abiotic stresses [3].

\footnotetext{
* Corresponding author: pavel.feduraev@gmail.com
} 
The canonical pathway for lignin formation, is the phenylalanine-mediated metabolic pathway. Lignin is synthesized from the aromatic amino acid 1-phenylalanine (Phe), which is converted by phenylalanine ammonia-lyase (PAL) into cinnamate. PAL is the first and key allosteric enzyme of phenylpropanoid metabolism [4]. However, to date, an additional alternative pathway for lignin synthesis has been shown to be more energetically efficient via the tyrosine ammonialyase pathway. The involvement of 1-tyrosine (Tyr) in the ligninmediated metabolic pathway, is also preformed by PAL. It should be noted that such activity has been shown only for cereal plants $[5,6]$.

Actually, PAL performs a "switch" from the primary plant metabolism to the secondary metabolism, leading to the formation of a wide range of secondary metabolites of phenolic nature [7]. PAL can be activated by a variety of environmental influences, making it an excellent inducer that triggers reactions aimed at synthesizing substances that ultimately affect plant tolerance. Aromatic amino acids, such as phenylalanine and tyrosine, which are terminal links in the shikimate pathway, act as substrates for PAL and play the role of peculiar effectors for this enzyme, stimulating the synthesis of secondary metabolites [8].

Thus, an increase in the number of phenolic compounds in cereal plants by means of substrate stimulation of key enzymes of the synthesis of this phenolic polymer is a promising method. Thus, it was shown that treatment of plants with the precursors of lignin synthesis (phenylalanine and tyrosine) resulted in a significant increase in phenols, an increase in phenylalanine amine lyase activity, and increased expression of ligninassociated genes [9]. Considering the above, the goal of this study is to evaluate the role of aromatic amino acids phenylalanine and tyrosine in lignin accumulation in wheat plants (Triticum aestivum L.).

\section{Materials and Methods}

Wheat (Triticum aestivum L.) of Vanek variety was obtained from the Seed Station of the Ministry of Agriculture of Kaliningrad region. Seeds were sterilized by incubation for $2 \mathrm{~h}$ in $10 \% \mathrm{NaClO}$, then washed at least 10 times with distilled water.

In order to study the separate influence of tyrosine and phenylalanine on metabolic processes, Triticum aestivum plants were grown on nutrient media containing $500 \mu \mathrm{M}$ of the corresponding amino acid throughout experiment. Seedlings at the age of 3-4 days were transplanted to liquid, intensively aerated, nutrient medium: 50\% Hoagland's solution. Samples grown solely on nutrient medium without the addition of aromatic amino acids served as a control. The plants were grown under fluorescent lamps at a photon flux density of $200 \mu \mathrm{mol} /(\mathrm{m} 2 \mathrm{~s})$, a 16 -hour photoperiod, and a temperature of $+25^{\circ} \mathrm{C}$.

The main pool of analyses was performed when the plants reached 30 days of age (corresponding to stage 4, 5 on the Feekes Feekes Scale). Vegetative photosynthetic parts of the plant, the stem and leaves, were used for experiments.

Protein extraction and kinetic analyses were carried out similarly as described by Cheng and Breen [10]. Plant tissue weighing $0.2 \mathrm{~g}$ was quickly frozen in liquid nitrogen and stored at $-80{ }^{\circ} \mathrm{C}$. Next, the sample was crushed and washed with $1 \mathrm{ml}$ of ice acetone, the resulting mixture was incubated at $-20^{\circ} \mathrm{C}$ for 15 minutes and centrifuged at $16,000 \mathrm{~g}$ for 15 minutes at $4{ }^{\circ} \mathrm{C}$. The precipitate was extracted by gentle spinning at $4{ }^{\circ} \mathrm{C}$ in the presence of $100 \mathrm{mM}$ borate buffer After 1 hour, the samples were centrifuged as above; the supernatant was used as the plant extract in kinetic analyses.

PAL activity was quantified by trans-cinnamic acid (TCA) production by taking absorption spectra at $290 \mathrm{~nm}$ [11] every minute for 20 minutes at $37{ }^{\circ} \mathrm{C}$ using a UV-3600, Shimadzu, Japan. The assay mixture contained $61 \mathrm{mM} 1$-phenylalanine, $30 \mathrm{mM}$ sodium-

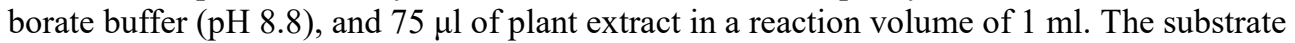
was added after a 10 -minute pre-incubation period at $37^{\circ} \mathrm{C}$. The plant extract preincubated 
in buffer without substrate was used as a blank experiment before each analysis. Each sample was analyzed in duplicate.

TAL activity was determined in a similar manner by monitoring p-coumaric acid (PCA) production at $310 \mathrm{~nm}$ [11]. $1 \mathrm{~mL}$ of the mixture for analysis contained $1.9 \mathrm{mM}$ 1-tyrosine, $30 \mathrm{mM}$ sodium-borate buffer $(\mathrm{pH} 8.8)$, and $75 \mu \mathrm{l}$ of plant extract. The temperature and preparation of the blank sample were identical to the PAL analysis.

The enzyme activity was expressed in units per mg of protein. One unit of PAL activity was defined as the amount of the enzyme that produced $1 \mu \mathrm{g}$ of cinnamic acid per hour. One unit of TAL activity was defined as the amount of the enzyme that produced $1 \mu \mathrm{g}$ of coumaric acid per hour. The 1-phenylalanine and 1-tyrosine substrates and their enzymatic transformation products trans-cinnamic acid and p-coumaric acid, respectively, were used as standards.

Peroxidase (POD) was determined according to the Malik and Sing method with some modifications [12]. To $2 \mathrm{ml}$ of phosphate buffer ( $\mathrm{pH} 6.0 / \mathrm{pH} \mathrm{7.0)}$ were added $100 \mu \mathrm{l}$ of plant extract and $1 \mathrm{ml}$ of o-dianisidine solution. The reaction was initiated by adding $100 \mu \mathrm{l}$ of $0.2 \mathrm{mM} \mathrm{H}_{2} \mathrm{O}_{2}$ and measuring the optical density at $(460 \mathrm{~nm})$ every 30 seconds to 5 minutes. Peroxidase activity was calculated using the o-dianisidine extinction coefficient, and enzyme activity was expressed in units per $\mathrm{mg}$ of protein. The protein concentration for both tests was determined by the Bradford method [13].

Determination of lignin content was carried out after appropriate preparation of plant samples tissues. It is necessary to remove all UV-absorbing compounds (primarily proteins) to avoid interference with the maximum absorption for lignin at $280 \mathrm{~nm}$. Dry samples $(0.3$ g) were homogenized in the presence of $50 \mathrm{mM}$ potassium-phosphate buffer, and then centrifuged. The precipitate was then washed several times and centrifuged successively after each washing procedure: twice in the presence of phosphate buffer $(\mathrm{pH} 7.0)$, three times in the presence of $1 \%$ Triton X-100 detergent, twice with $1 \mathrm{M} \mathrm{NaCl}$ buffer at $\mathrm{pH} 7.0$, twice with distilled water, and twice with acetone. The precipitate was dried in a desiccator $\left(60{ }^{\circ} \mathrm{C}, 24 \mathrm{~h}\right)$ and cooled in a vacuum desiccator. The resulting dry matter was defined as a protein-free cell wall fraction [14].

The cell wall sample $(20 \mathrm{mg})$ was placed in a centrifuge tube and $0.5 \mathrm{ml}$ of $25 \%$ acetyl bromide (vol. / vol. in glacial acetic acid) was added, and incubated at $70{ }^{\circ} \mathrm{C}$ for $30 \mathrm{~min}$. After complete decomposition, the sample was rapidly cooled in an ice bath and then mixed with $0.9 \mathrm{ml}$ of $2 \mathrm{M} \mathrm{NaOH}, 0.1 \mathrm{ml}$ of $5 \mathrm{M}$ hydroxylamine- $\mathrm{HCl}$, and ice-cold acetic acid, sufficient to completely solubilize the lignin extract. After centrifugation $(1,400 \times \mathrm{g}, 5 \mathrm{~min})$ the supernatant optical density was measured at $280 \mathrm{~nm}$ [15]. The results were expressed in $\mathrm{mg}$ of lignin per $\mathrm{g}^{-1}$ of the cell wall.

All values presented are averages for at least three repetitions. The significance level was set to $\mathrm{p} \leq 0.05$. Statistical data analysis was performed using SigmaPlot 12.3 (Systat Software GmbH, Erkrat, Germany). The Shapiro-Wilks test was used to check normality; Additionally, the experimental data were tested for homogeneity of variance.

All chemicals used in the experiments were of analytical purity obtained from commercial sources. Distilled water was used throughout the experiment. Working standard solutions were prepared (nutrient medium, in particular) by diluting the stock solutions.

\section{Results and Discussion}

The activity of a key enzyme in the biosynthesis of phenolic compounds was evaluated (Figure 1). It is worth noting that PAL of cereal plants can use tyrosine as an alternative substrate; thus, the tyrosine-ammonialyase activity of plant extracts was tested). 

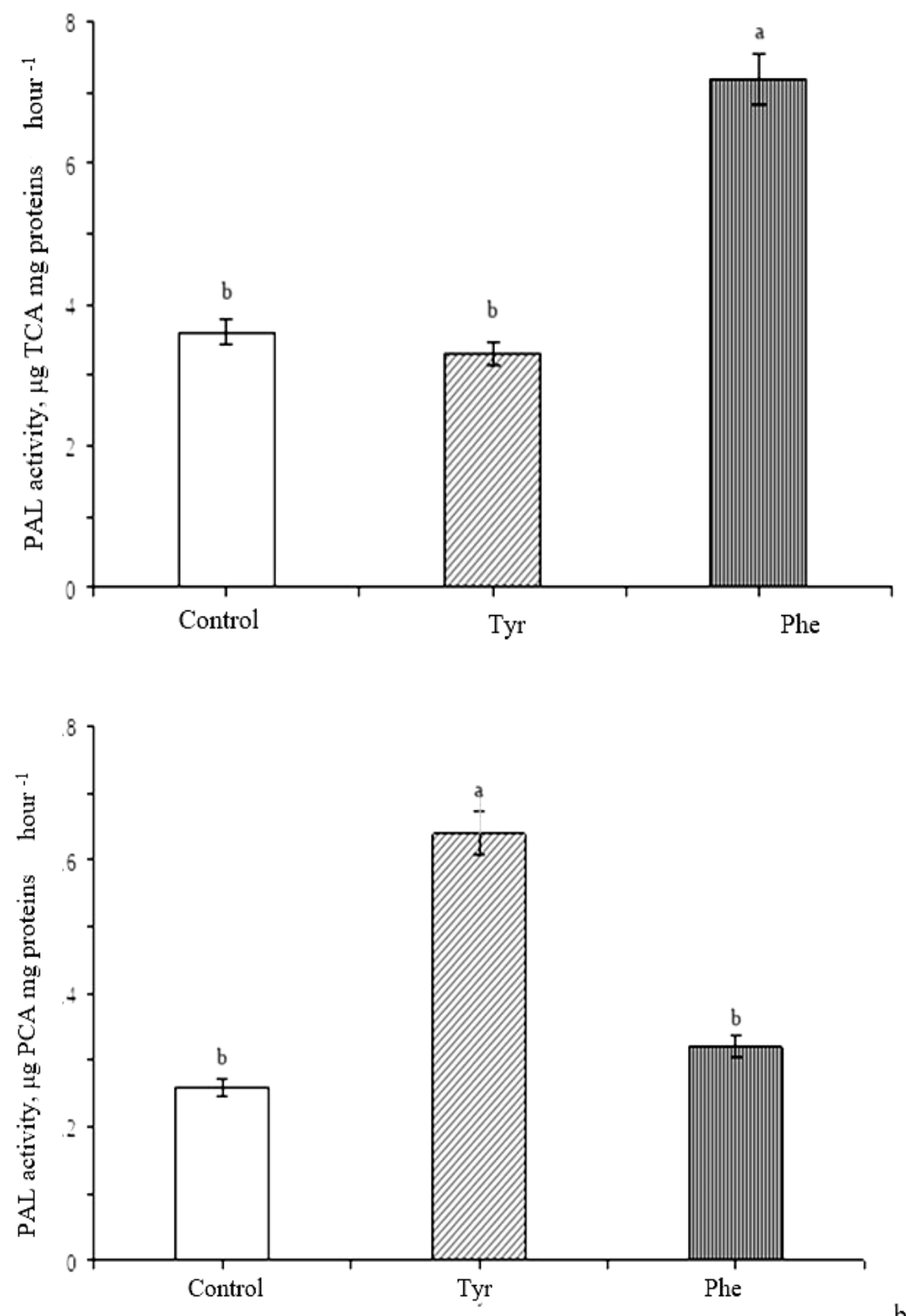

b

Fig.1. The PAL(a) and TAL(b) activity in wheat samples incubated on a nutrient medium with the addition of 500 microns of phenylalanine and tyrosine, respectively. Columns marked with different letters show significant differences at $(\mathrm{p} \leq 0.05)$ according to Tukey's test.

There was a significant $(\mathrm{p} \leq 0.05)$ increase in the PAL and TAL activity compared to the control, but only when the results were normalized for the corresponding products of enzymatic transformation (PAL for TCA and TAL for PCA). Experimental Vanek wheat plants transferred to nutrient media containing $500 \mu \mathrm{M}$ phenylalanine and tyrosine and exposed under these conditions during the entire growth period showed a significant more 
than twofold increase in PAL and TAL activity. The rate of involvement in tyrosine metabolism via tyrosine ammonialyase PAL activity was slightly lower $(0.64 \mu \mathrm{g}$ PCA mg proteins ${ }^{-1}$ hour $^{-1}$ in tyrosine-exposed plants compared with control plants: $0.26 \mu \mathrm{g}$ PCA mg proteins ${ }^{-1}$ hour $^{-1}$ ) than the rate of involvement in phenylalanine metabolism through PAL.I

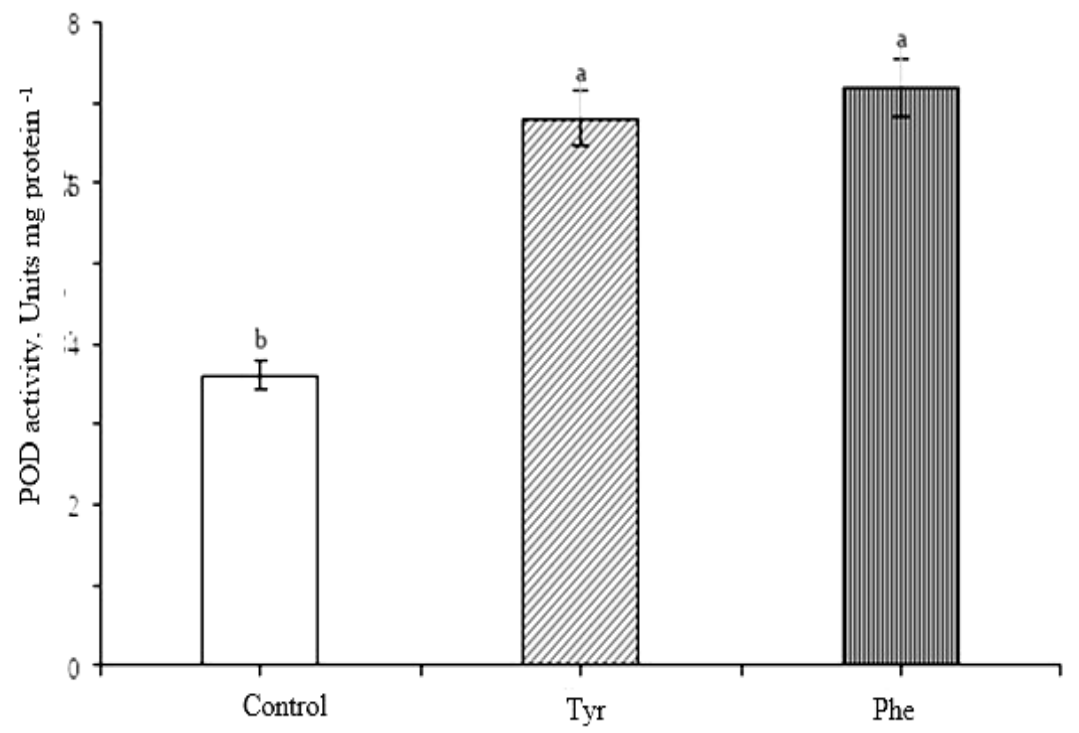

Fig. 2. POD activity in wheat samples incubated on a nutrient medium with the addition of 500 microns of phenylalanine and tyrosine, respectively. Columns marked with different letters show significant differences at $(\mathrm{p} \leq 0.05)$ according to Tukey's test.

POD activity was shown to increase in the presence of both effectors (Figure 2). Plants grown on medium with phenylalanine were characterized by more than a twofold increase in POD activity compared with control plants $(7.2 \mathrm{units} / \mathrm{mg}$ protein in comparison with the level of control plants: 3.5 units $/ \mathrm{mg}$ protein). A similar trend was observed when plants were exposed to tyrosine (6.8 units/mg protein in comparison with the level of control plants: 3.5 units/mg protein).

The selected methods made it possible to determine PAL/TAL activity as well as POD activity in the same extracts. Cultivation of plants under conditions of constant exposure to media enriched with aromatic proteinogenic amino acids led to a significant $(p \leq 0.05)$ increase in the activity of selected enzyme groups. However, it should be remembered that these enzymatic systems are included in the metabolism of phenylpropanoids at different stages.

There are two main stages in lignin production: monolignol biosynthesis, which is triggered by PAL, and monolignol polymerization by free-radical coupling, which is served by redox-active enzymes and, in particular, POD [16].

The enzymes that catalyze monolignol biosynthesis have been well studied in the model plant Arabidopsis. Genetic modulation of these enzymes has been shown to dramatically alter lignin accumulation and/or composition. Monolignols are synthesized from phenylalanine through the phenylpropanoid pathway. In the phenylpropanoid pathway, there are three enzymes: phenylalanine ammonia-lyase (PAL), cinnamate-4-hydroxylase $(\mathrm{C} 4 \mathrm{H})$, and 4-coumarate:CoA ligase $(4 \mathrm{CL})$ catalyze the first three stages in the reaction sequence of the phenylpropanoid pathway. Genetic inhibition of the PAL, C4H, and 4CL genes has been shown to significantly reduce lignin content in the plant species studied [7, 17-19]. 
After biosynthesis, monolignols polymerize to form lignin. Peroxidases and laccaseases are thought to be the key enzymes that catalyze monolignol polymerization, although the experimental data are incomplete. Studies of the genes encoding peroxidase and laccase in Arabidopsis demonstrated a close relationship between these enzymes and lignin accumulation in secondary cell walls. It was found that peroxidase gene double mutants in Arabidopsis plants are characterized by a reduced lignin content by an average of $11-25 \%$ [20]. The results correlate with the theoretical literature.

An increase in the activity of key enzymes responsible for the synthesis of lignin structures (PAL) and lignin monomer condensation (POD) led to a significant increase in lignin levels in the cell walls of experimental plants (Figure 3).

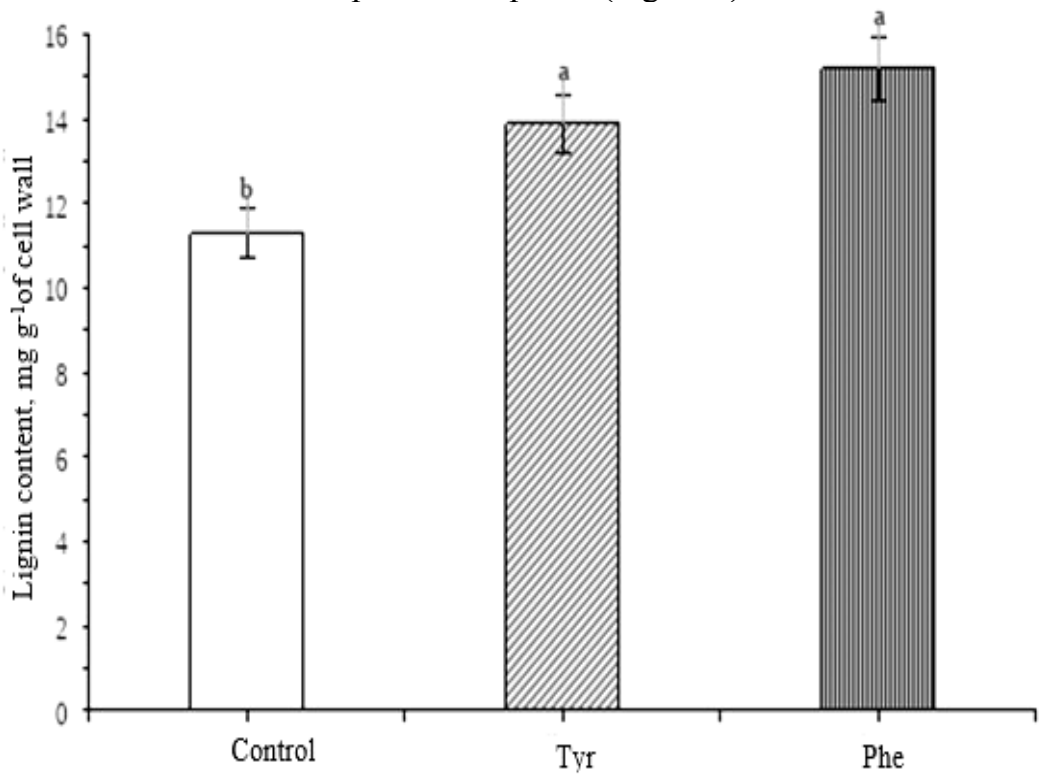

Fig. 3. Lignin content in wheat samples incubated on nutrient media with the addition of $500 \mu \mathrm{M}$ phenylalanine and tyrosine, respectively. Columns marked with different letters show valid differences at $(\mathrm{p} \leq 0.05)$ according to Tukey's test.

The experimental groups of plants exposed to nutrient media with the addition of amino acids, effectors in relation to PAL, show significantly $(p \leq 0.05)$ more effective accumulation of lignin at this stage of ontogenesis (on average by $20 \%$ compared to the control). It is interesting to note that the 4-5 phase of plant development according to the Ficky scale is characterized by active laying of the secondary cell wall (determined by the presence of lignin in its structure) and intensification of this process can be an excellent reserve for successful plant development in the later stages.

Lignin structures are a product of the phenylpropanoid pathway, and intensification of this metabolic pathway via PAL can additionally lead to the biosynthesis of a number of phenolic compounds. This group of physiologically active compounds can be involved both in plant protection and in ensuring adequate redox balance of the plant cell. Such compounds include: phytoalexins, stilbens, coumarins, and flavonoids [21, 22].

\section{Conclusions}

This study analyzed the effect of aromatic proteinogenic amino acids (phenylalanine and tyrosine) on the lignin level of the cell wall of Triticum aestivum L. A significant $(\mathrm{p} \leq 0.05)$ increase in the activity of PAL, TAL, and POD enzymes was observed in wheat samples 
exposed on phenylalanine- and tyrosine-enriched media. A $20 \%$ increase in lignin levels was shown in experimental plants compared to controls.

In addition to the lignin physiological functions, it should be noted that lignin is also a key ingredient in raw materials and plant biomass. Lignin provides high energy density biomass for pyrolysis and direct combustion, and is a major source of renewable aromatic precursors for the chemical industry. Lignin can become an excellent alternative source of aromatic compounds and their derivatives, and the search for ways to intensify the biosynthesis of this polymer remains an urgent biotechnology task.

\section{Acknowledgements}

This work was financially supported by the Russian Foundation for Basic Research and the Ministry of Economic Development, Industry, and Trade of the Kaliningrad Region (under Agreement No. 28-c/2020) under Project No. 19-44-393001.

\section{References}

1. J. Rencoret et al., Plant Physiology, 155, 667 (2011)

2. L. Jones, A. R. Ennos, S. R. Turner, The Plant J., 26, 205 (2001)

3. S. Sattler, D. Funnell-Harris, Frontiers in plant science, 4, 70 (2013)

4. J. Q. Kong, RSC Advances., 5, 62587 (2015)

5. H. A. Maeda, Nature plants, 2, 1 (2016)

6. J. Barros, et al., Nature plants, 2, 16050 (2016)

7. A. Rohde, et al., The Plant Cell., 16, 2749 (2004)

8. Y. Qian, et al., Nat. Commun., 10, 1 (2019)

9. P. Feduraev, et al., Plants, 9, 476 (2020)

10. G. W. Cheng, P. J. Breen, J. Am. Soc. Hortic., 116, 865 (1991)

11. J. Rösler, F. Rösler, F. Amrhein, J. Schmid, Plant Physiol., 113, 175 (1997)

12. C. P. Malik, M. B. Singh, Plant Enzymology and Histoenzymology, 50 (1980)

13. M. M. Bradford, Anal Biochem., 72, 248 (1976)

14. F. C. Moreira-Vilar, et al., PloS one, 9 (2014)

15. W. J. Barnes, C. T. Anderson, Bio-Protoc., 7, 2149 (2017)

16. J. Yoon, H. Choi, G. An, J. Integr. Plant Biol., 57, 902 (2015)

17. F. Chen et al., Plant J., 48, 113 (2006)

18. R. Vanholme, K. Morreel, J. Ralph, W. Boerjan, Curr. Opin. Plant Biol., 11, 278 (2008)

19. J. P. Wang, et al., Nat. Commun., 9, 1579 (2018)

20. J. Shigeto, et al., J. Integr. Plant Biol., 57, 349 (2015)

21. V. V. Lozovaya et al., Planta, 225, 665 (2007)

22. C. M. Fraser, C. Chapple, The phenylpropanoid pathway in Arabidopsis (2011) 